\title{
High Performance Water-based Drilling Fluids-A High Efficiency Muds Achieving Superior Shale Stability While Drilling Deepwater Well with HPHT in South China Sea
}

\author{
Li Huaike*, Geng Tie, Guo Lei, Luo Jiansheng \\ China Oilfield Services Limited, Langfang, China \\ Email address: \\ lihk6@cosl.com.cn (Li Huaike), gengtie@cosl.com.cn (Geng Tie), guolei5@cosl.com.cn (Guo Lei), luojsh@ cosl.com.cn (Luo Jiansheng) \\ ${ }^{*}$ Corresponding author
}

To cite this article:

Li Huaike, Geng Tie, Guo Lei, Luo Jiansheng. High Performance Water-based Drilling Fluids-A High Efficiency Muds Achieving Superior Shale Stability While Drilling Deepwater Well with HPHT in South China Sea. Science Journal of Energy Engineering.

Vol. 7, No. 4, 2019, pp. 98-103. doi: 10.11648/j.sjee.20190704.16

Received: September 18, 2019; Accepted: November 5, 2019; Published: November 13, 2019

\begin{abstract}
In deepwater drilling operation, low temperature, high pressure, gas hydrate, narrow density window are the major challenges for drilling fluids to meet, and with the increasing depth drilled, high temperature and high pressure condition was occurred in deepwater well. In the other side, Oil based muds (OBM) and synthetic based muds (SBM) are limited in using because of the strict environment rules in the South China Sea. In deepwater HTHP well, shale hydration, dispersion and Equivalent Circulation Density (ECD) caused by rheology change with high temperature difference are the two critical problems. Therefore, petroleum service institutes and companies take much time and money on research to develop a high performance water-based mud system (HPWBM) to solve these problems and improve drilling efficiency. In the paper, a new method to estimate amine derivatives was proposed, the specific test steps was introduced in detail, and secondly a High efficiency muds (HEM) are selected and the main properties were evaluated in lab such as rheological properties at lower temperature, shale inhibition and anti-accretion. Finally, the system was applied successfully in LS project in the South China Sea. The results showed that HEM system delivered high drilling performance such as shale stability, high pressure and high temperature (HPHT) resistance, lubricity and high rate of penetration (ROP) with no wellbore problems, and the system is suitable for deepwater HTHP well operation.
\end{abstract}

Keywords: Deepwater, HTHP, HPWBM, Inhibition

\section{Introduction}

With the increasing demand for oil \& gas and the development of ocean petroleum industry, many oil companies have focused on oil and gas buried in deepwater and ultra-deepwater reservoir $[1,2]$. Low temperature, high pressure, narrow density window between fracture and pore pressure, gas hydrate and rich shale in drilled formation are the major challenges for drilling fluids [3-5]. In order to satisfy the requirements of deepwater drilling operations, many petroleum service institutes and companies take much time and money on research to develop a High Performance Water-based Mud (HPWBM) to drilling shale formation in deepwater and too much money to improve drilling efficiency [6-9].

In the past 20 years, hundreds of wells had been drilled, and various Non-Aqueous Drilling Fluids (NADF) and
Water-based Mud (WBM) have been used in deepwater zones [10-14]. But NADF have some undeniable disadvantages, such as high cost, environmental limitations, disposal problems, and health and safety issues. Therefore, WBM had a wide development and applications in the past year, such as PERFORMAX, ULTRADRILL and HYDROGUARD. They all have the following criteria:

i. Maximum shale inhibition and wellbore stability

ii. Low accretion and bit balling tendencies

iii.Good, stable and easy to maintain properties

iv. Flexibility in density and base brine selection

v. Thermal stability from low temperature to high

vi. Environmental friendly

In this paper, a high efficiency muds (HEM) was selected based on an excellent amine derivative, and a new methodology was introduced to evaluate the inhibition of 
amine inhibitor. We also address operator's criteria of evaluating the HEM system, and finally summarize the whole achievements of the HEM system's drilling campaign.

\section{Filed Background}

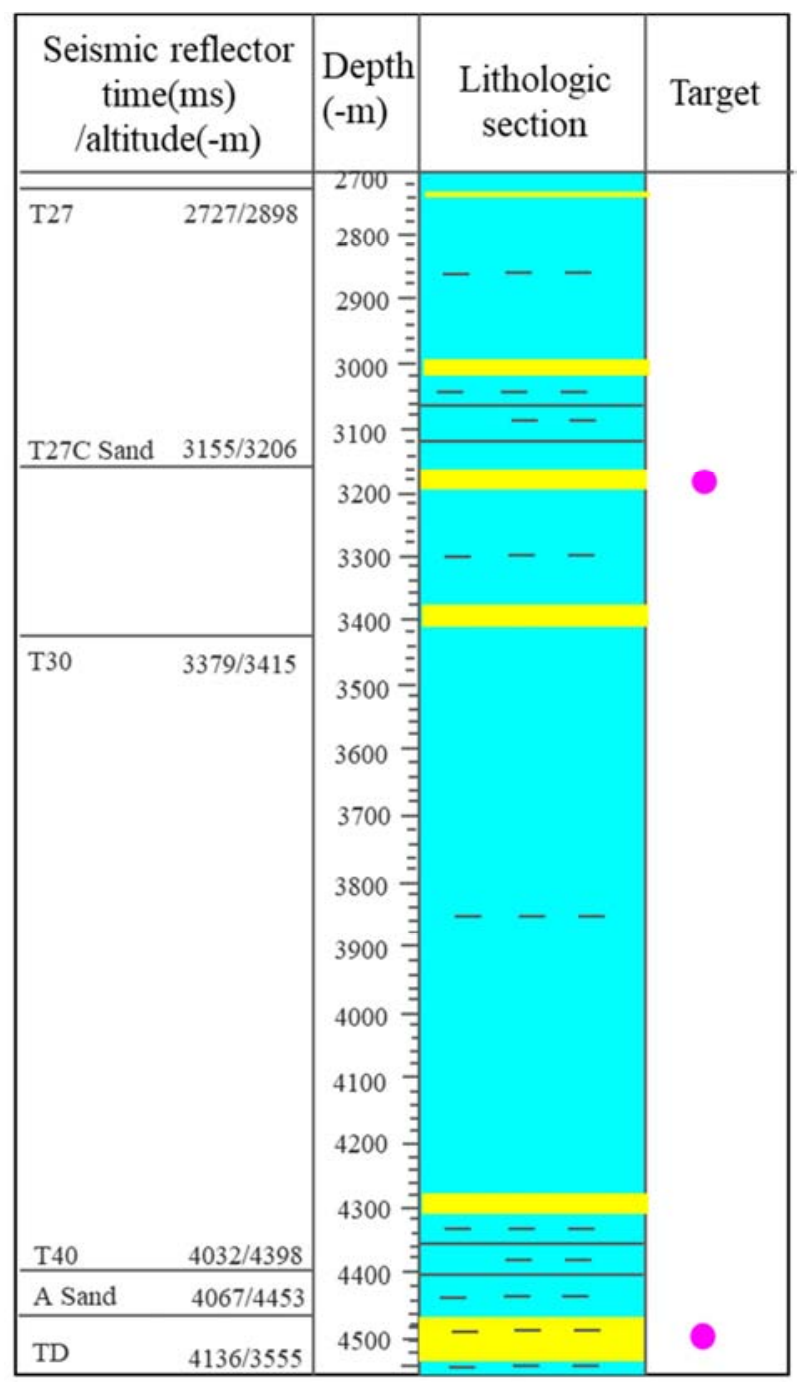

Figure 1. Lithology of target well.
The target well drilled is a vertical deepwater well with high pressure and high temperature (BHT is $156^{\circ} \mathrm{C}$ ). Yinggehai group, Huangliu group and Meishan group have been drilled successively; the lithology (Figure 1) of the formation is mainly rich dark grey claystone and silty claystone, partially with siltstone and fine sandstone. The formation pressure coefficients are as follows: above $2,000 \mathrm{~m}$ is 1.00 , $2,000-3,200 \mathrm{~m}$ is 1.00 to $1.22,3,200-4,400 \mathrm{~m}$ is 1.22 to 1.70 and $4,400-4,555 \mathrm{~m}$ is 1.70 to 1.83 .

\section{Selection Criteria for HEM}

The primary reasons driving the operator to switch drilling fluids from SBM to WBM was the increasing environmental awareness and few application case of SBM in this area. When OBM or SBM system is used in offshore, the rigorous design investigation and environmental assessment by government department must be done, and the operator do not be inclined to OBM or SBM [15-16]. Meanwhile, there is a stronger restriction on ocean discharges of SBM and oil-contaminated cuttings. If the local government leans toward a zero discharge limit, the operator must transfer the oil-contaminated drilling cuttings to land for further management and treatment. The combined costs of SBM, solid control, waste transportation treatment and management will diminish the attractiveness of SBM system.

The secondary consideration was that the operator has already be costumed to using HEM system for shale inhibition in South China Sea, approximately 20 deepwater exploratory wells were drilled in the past 10 years. The system has showed success in achieving high shale inhibition, preventing clay and cutting hydration, and reducing bit balling without any hole-related problems.

\section{HEM Design and Properties}

HEM system is a high performance water-based muds (HPWBM) for deepwater and ultra-deepwater well drilling without bentonite, which could achieve the requirement of drilling operation and environmental protection by an exclusive, extra-inhibition approach. The basic formula of HEM was listed in Table 1.

Table 1. The basic formula of HEM.

\begin{tabular}{lll}
\hline Product name & Primary function & Dosage \\
\hline PF-UHIB & Shale stabilizer & $2 \sim 4 \% \mathrm{~V} / \mathrm{V}$ \\
PF-UCAP & Clay-dispersion inhibitor & $0.5 \sim 1 \%$ \\
PF-HLUB & Anti-accretion, lubricity and ROP enhancement & $2 \sim 3 \% \mathrm{~V} / \mathrm{V}$ \\
PF-FT-1 & Well stability & $1 \sim 2 \%$ \\
PF-XC & Rheology control & $0.1 \sim 0.3 \%$ \\
PF-FLOTROL & Filtration control & $1.5 \sim 2 \%$ \\
$\mathrm{NaCl}$ & Hydrate inhibitor/Weight material & As needed for mud weight \\
KCl & Inhibitor & $5 \sim 7 \%$ \\
Barite & Density control & As needed for mud weight \\
\hline
\end{tabular}

\subsection{Inhibition Test of PF-UHIB}

From the lithology information, we can see that upper section is rich in shale and clay and easy to disperse and swell which is the main reason to wellbore instability. An amine derivative PF-UHIB was adopted to improve the shale inhibition, minimize bit balling and accretion. In the paper, a new methodology called water separation percent (WSP) was put forward to test the properties of amine 
inhibitor [17], It's definition is a percent of free water separated with total slurry volume. and is calculated by the following formula.

$$
\mathrm{WSP}=\frac{\mathrm{V}_{\mathrm{fw}}}{\mathrm{V}} \times 100 \%
$$

$\mathrm{V}_{\mathrm{fw}}$ - the volume of free water separated, $\mathrm{mL} ; \mathrm{V}$ - total volume, $\mathrm{mL}$.

In WSP experiment, different concentration bentonite was added to distilled water (DW) contained 3\% amine derivatives, then the slurry was aged at $100^{\circ} \mathrm{C}$ for 16 hours, then poured the slurry in $250 \mathrm{~mL}$ cylinder to let stand 6 hours. Figure 2 and figure 3 show the contrast of WSP in different concentration of bentonite slurry. They showed that WSP decrease with the increasing bentonite in slurry and PF-UHIB inhibitor has an excellent inhibition to shale.

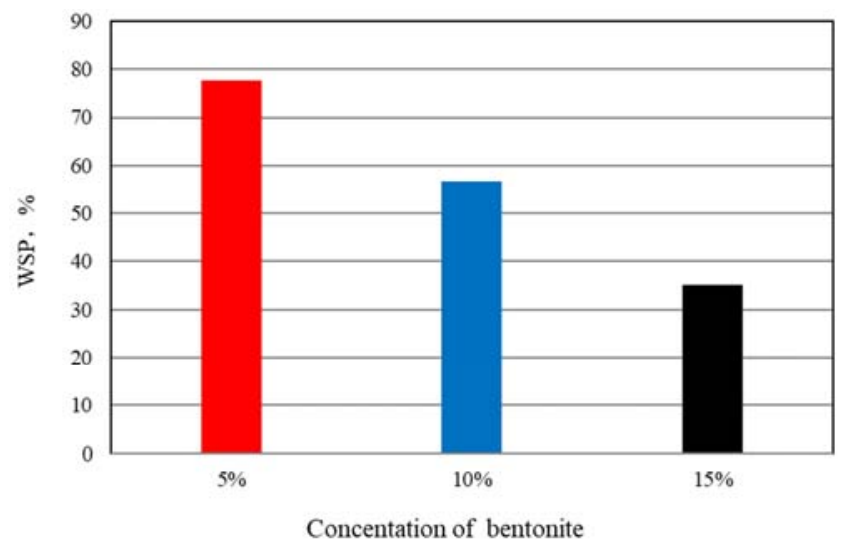

Figure 2. WSP of PF-UHIB in different concentration of bentonite slurry.

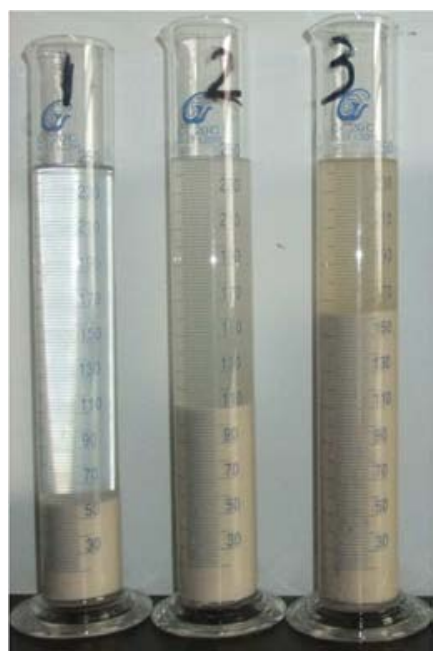

Figure 3. Contrast of WSP in different concentration of bentonite slurry.

The influence of polyamine inhibitor on clay surface was tested by scanning electron microscopy (SEM). The results are shown in figure 4 and figure 5. It illustrates that the inhibitor can absorb clay layers and makes them closer to each other. When adding inhibitor, the microstructure of clay is more compact, while the clay without inhibitor is granular, and the distance between them is larger.

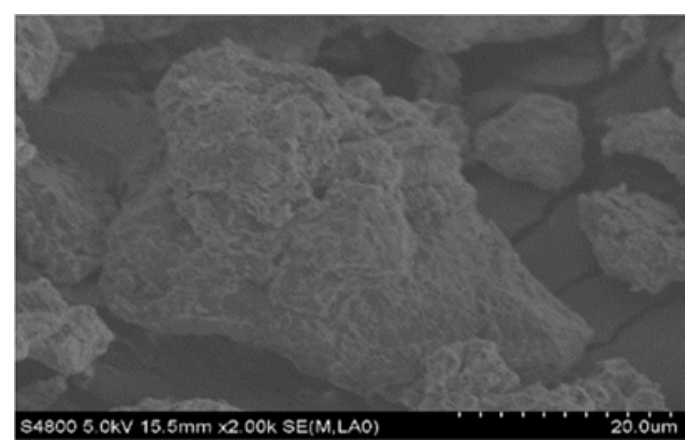

Figure 4. Clay SEM photo with no inhibitor $(\times 2000)$.

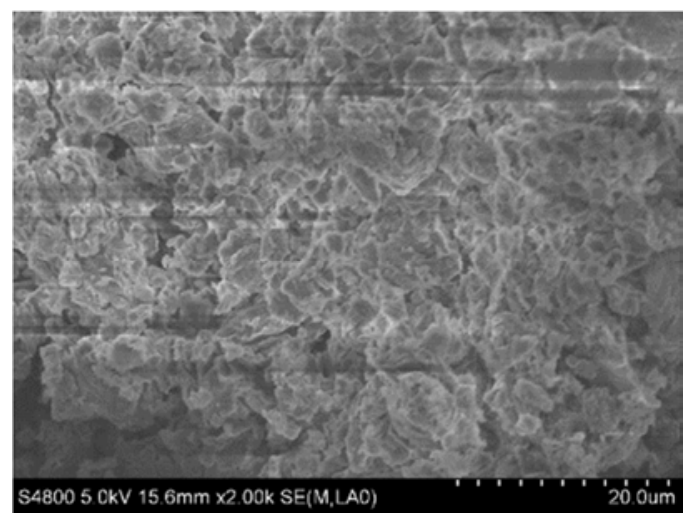

Figure 5. Clay SEM photo with $1.5 \%$ inhibitor $(\times 2000)$.

\subsection{Laboratory Experiments on HEM}

\subsubsection{Rheological Properties at Low Temperature}

Drilling fluids used in deepwater drilling operation was cooled in riser and warmed up in formation bellow mud line, these two opposite states alternate ceaselessly in drill-in operation. Drilling fluids had different properties with temperature, increasing with high temperature and decreasing with low temperature, which effected well cleaning, cutting suspending, annular hydraulics and mud treatment directly. Based on FanniX77 Automatic Rheometer, Rheological properties at different temperatures $\left(4^{\circ} \mathrm{C}, 8^{\circ} \mathrm{C}, 15^{\circ} \mathrm{C}, 25^{\circ} \mathrm{C}\right.$, $40^{\circ} \mathrm{C}, 50^{\circ} \mathrm{C}$ ) between cooling and warming-up were recorded in lab. Figure 6, Figure 7, Figure 8 showed the test results, which demonstrated HEM had a good rheological properties at low temperature and superior thermal stability from lower to higher.

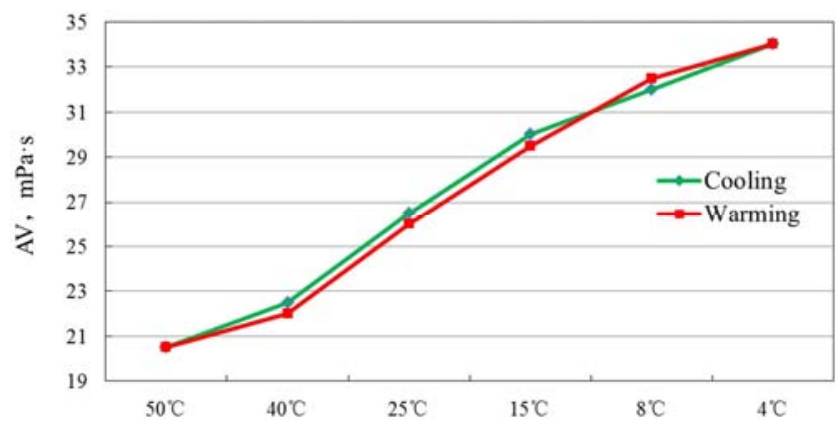

Figure 6. AV curve of HEM between cooling and warming-up stage. 


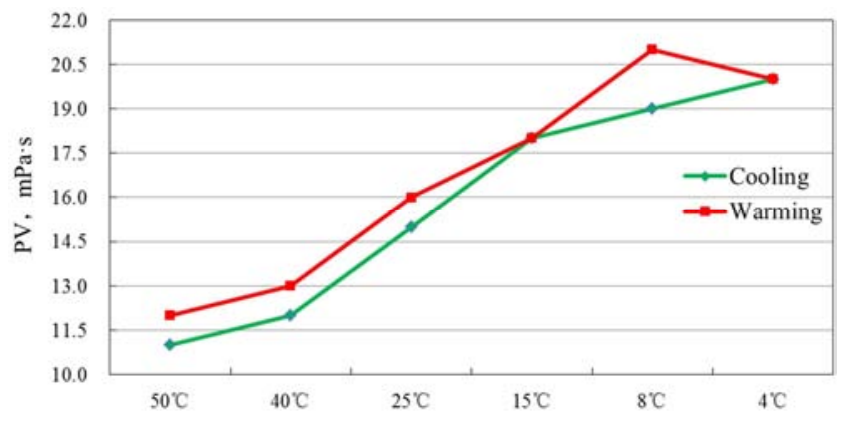

Figure 7. PV curve of HEM between cooling and warming-up stage.

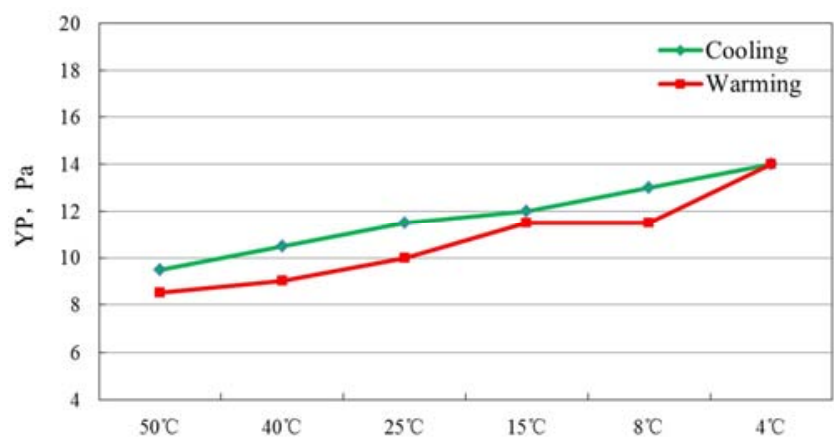

Figure 8. YP curve of HEM between cooling and warming-up stage.

\subsubsection{Shale Inhibition}

Qualitative shale recovery test was done on HEM to evaluate qualitatively of shale inhibition performance with easily dispersed shale named HolePLUG. The same test was carried out on PHPA/KCl system which was widely used in China BoHai zone. The results can be seen in Figure 9. What can be seen from the results was that HEM had higher shale recovery than PHPA/KCl no matter Hot Recovery, Durability Recovery or Second Recovery. Therefore, HEM was a good WBM for drilling deepwater formation contained high dispersing shale. Figure 7 showed the Second recovery of each mud in distill water, HEM had a higher integrity than $\mathrm{PHPA} / \mathrm{KCl}$ system.

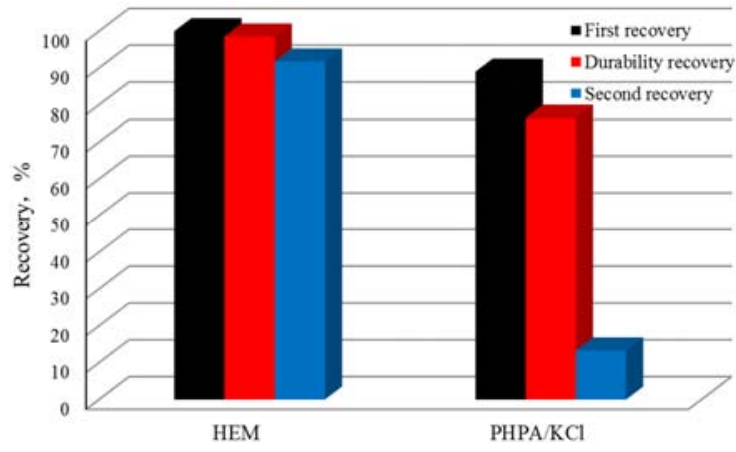

Figure 9. Recovery results of $\mathrm{HEM}$ and $\mathrm{PHPA} / \mathrm{KCl}$.

\subsubsection{Anti-accretion}

Shale formation could easily produced mud-ball in drill-in operation, which caused higher torque, effected Rate of Penetration (POP) and hole stability. The lab bit-balling test showed HEM had little gumbo phenomenon compared with PHPA $/ \mathrm{KCl}$, only $3.13 \%$, see Figures 10 and 11 . The main reason was that PF-HLUB added in the syestem can form a film between clay and bit interface to reduce the adhesion of the clay to bit.

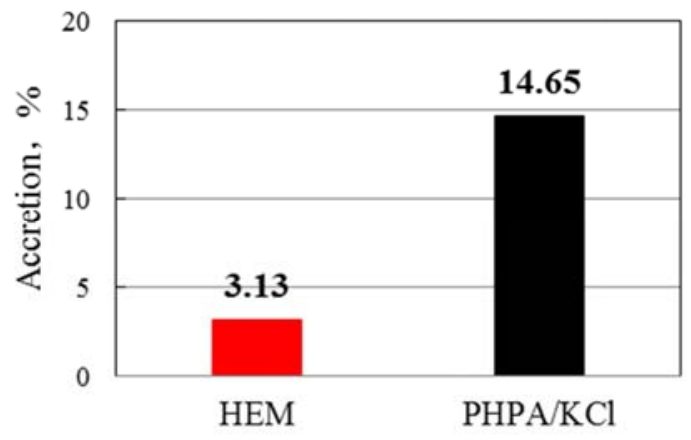

Figure 10. Anti-accretion results of HEM and $\mathrm{PHPA} / \mathrm{KCl}$.

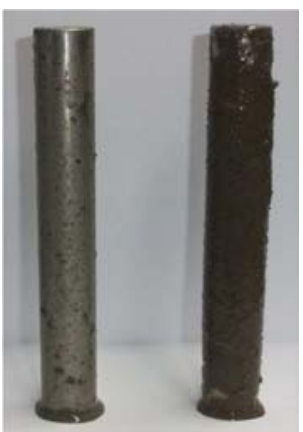

Figure 11. Anti-accretion results of HEM and PHPA/KCl (Left HEM, right $\mathrm{PHPA} / \mathrm{KC}$ ).

\section{Application}

LS1-1 well was an exploratory vertical deepwater well drilled in 2015 with $988 \mathrm{~m}$ water depth, and there were four sections $(17 * 20$ in, $14-3 / 4 * 17-1 / 2$ in, $12-1 / 4$ in and $8-3 / 3$ in) drilled with HEM, the 36 in and 26 in section were drilled with sea water (SW) and pre-hydrated bentonite (PHB). The ROP in the section drilled with HEM was average $11.7 \mathrm{~m} / \mathrm{h}$, the well TVD was $4448 \mathrm{~m}$ with $1.94 \mathrm{SG}$ mud weight. Figure 12 was the well structure.

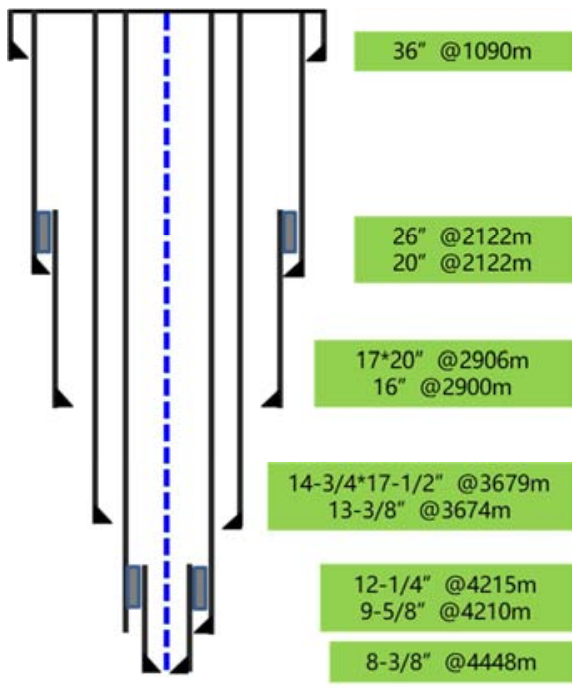

Figure 12. Well structure. 
Table 2 illustrates system properties at the final TD, the results show that the HEM system provides good rheological properties with low MBT and filtration. In field application, the system showed good inhibition to shale and excellent flow pattern (figures 13, 14, 15, 16).

Table 2. End properties of the HEM system.

\begin{tabular}{ll}
\hline Name & Value \\
\hline Mud weight, SG & 1.94 \\
$\mathrm{FV}, \mathrm{s}$ & 69 \\
$\mathrm{PV}, \mathrm{mPa} \cdot \mathrm{s}$ & 66 \\
$\mathrm{Gel} 10^{\prime \prime} / 10^{\prime}, \mathrm{lb} / 100 \mathrm{ft}^{2}$ & $4 / 9$ \\
$\mathrm{MBT}, \mathrm{kg} / \mathrm{m}^{3}$ & 11 \\
$\mathrm{API}$ filtration $(\mathrm{mL})$ & 2.0 \\
$\mathrm{HTHP}$ filtration $@ 150^{\circ} \mathrm{C}(\mathrm{mL})$ & 12.0 \\
$\mathrm{pH}$ & 11 \\
\hline
\end{tabular}

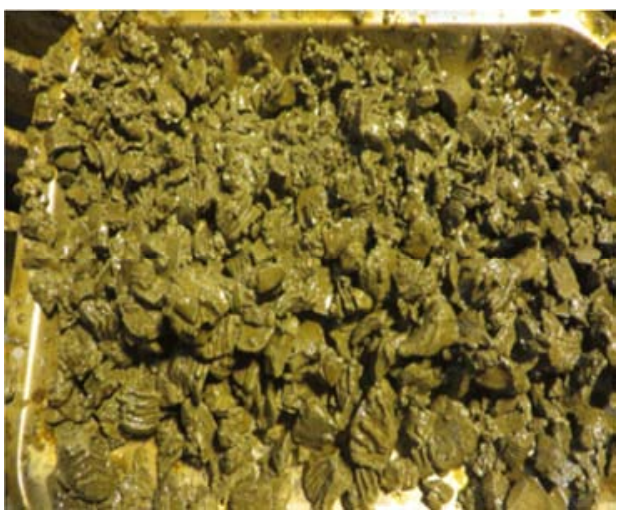

Figure 13. Drilling cuttings.

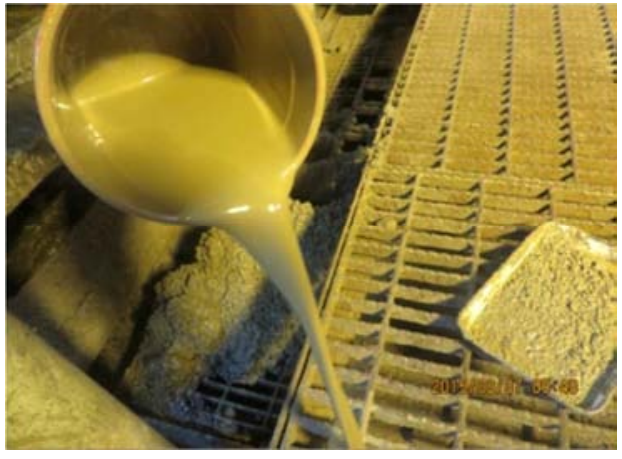

Figure 14. Flow state of HEM system curve.

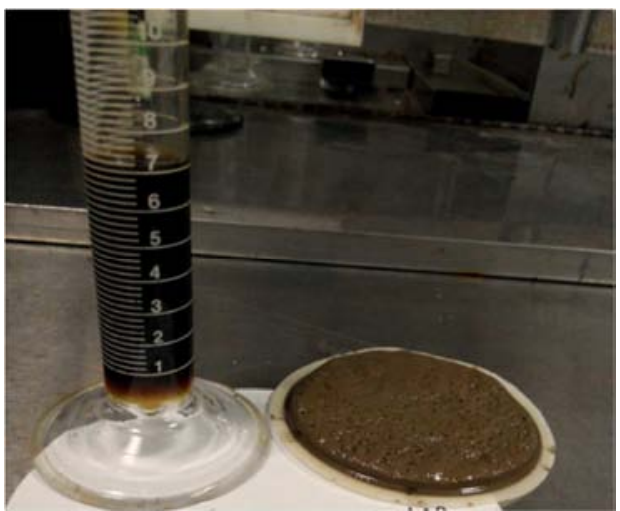

Figure 15. Filtration and cake.

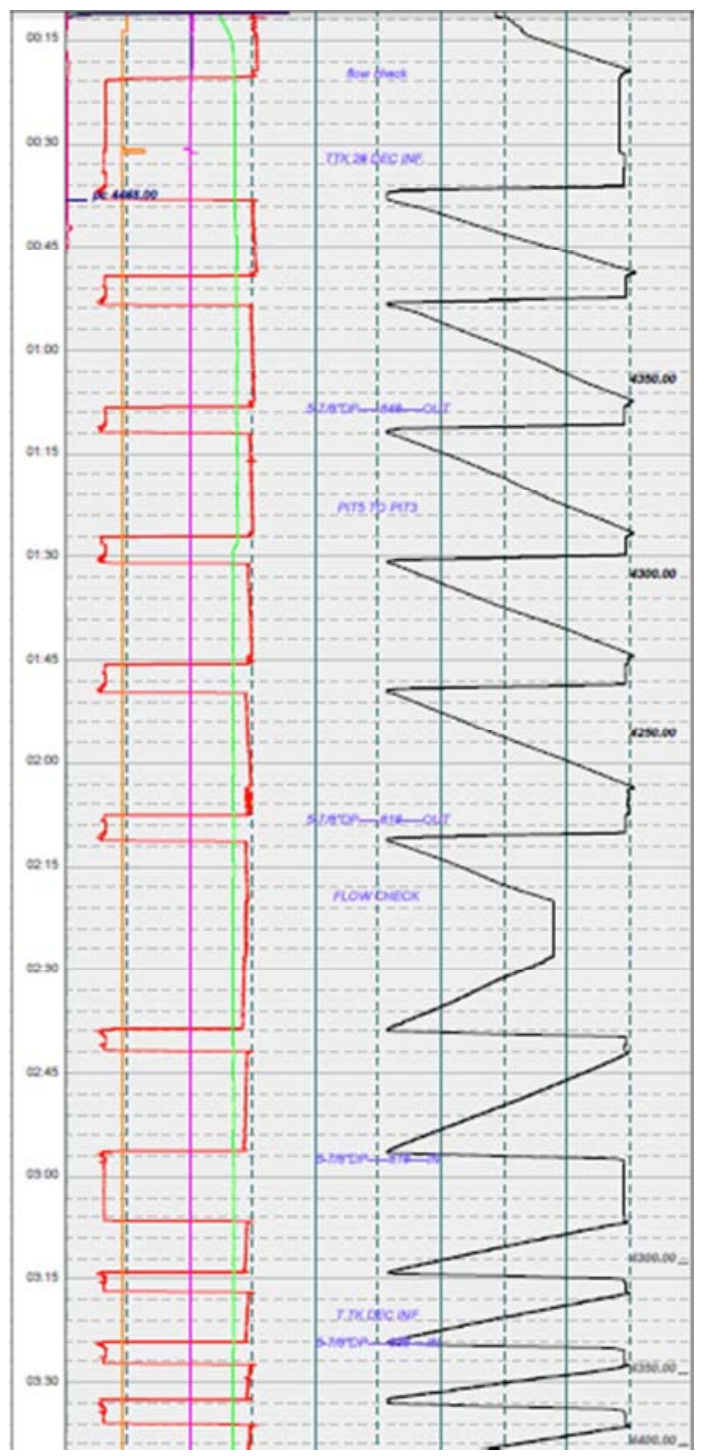

Figure 16. Tirp curve.

\section{Conclusion}

A new methodology named WSP was introduced to evaluate shale inhibition of amine derivative and the new method was used to evaluate PF-UHIB which showed a good inhibition to bentonite slurries. HEM system is suitable in South China Sea deepwater well drilling operation, and the well application proved that HEM system selected is an excellent alternative to OBM or SBM. The system delivered high drilling performance such as shale stability, clay inhibition, lubricity and high rate of penetration (ROP) with no wellbore problems, and the system provide improved HSE and eliminated the rig costs associating with drilling and waste management.

\section{References}

[1] Luo Jiansheng, Li Zili, Luo Man, et al. "Status Quo of the Development of Deep Water Drilling Fluids Worldwide", Drilling Fluid \& Completion Fluid, 2018, 35 (2): 1-7. 
[2] Thiago Pontes, Fernando Barbosa, Silvio Cosendey.: "Managed Pressure Drilling in Deepwater Brazil Presalt Severe-Loss Scenario", SPE189998 presented at SPE/IADC Managed Pressure Drilling and Underbalanced Operations Conference and Exhibition, 2018, 17-18 April. 1-6.

[3] Jorge Capeto, Matt Stahl Kenneth Bhalla, et al. "Challenges of Drilling Operations in Extreme Deepwater", OTC28081 presented at Offshore Technology Conference, 2017, 24-26 October.

[4] Steven Hancock, Ray Boswell, Tim Collett, eta.: "Development of Deepwater Natural Gas Hydrates", OTC29374 presented at Offshore Technology Conference, 6-9 May. 1-12.

[5] Xin Zhao, Zhengsong Qiu, Mingliang Wang, et al. "Silicate and Aluminum-Based Drilling Fluids for Stabilizing the Wellbore in Deepwater Drilling”, ISOPE-I-19-666 presented at the 29th International Ocean and Polar Engineering Conference, 2019, 16-21 June. 1-5.

[6] Vikrant Wagle, Abdullah S, Al-Yami, et al. "High Density Drilling Fluids for Managed Pressure Drilling", SPE192248 presented at SPE Kingdom of Saudi Arabia Annual Technical Symposium and Exhibition, 2018, 23-26 April. 1-18.

[7] Liu, Xiaodong, Xie, Binqiang, Gao, Yonghui, et al. "Development of Low Toxicity and High Temperature Polymer Drilling Fluid for Environmentally Sensitive Offshore Drilling", SPE190967 presented at IADC/SPE Asia Pacific Drilling Technology Conference and Exhibition, 2018, 27-29 August. 1-12.

[8] Anuradee Witthayapanyanon, Jerorme Leleux, Julien Vuillemet. "High Performance Water-Based Drilling Fluids-An Environmentally Friendly Fluid System Achieving Superior Shale Stabilization While Meeting Discharge Requirement Offshore Cameroon", SPE163502 presented at SPE/IADC Drilling Conference and Exhibition, 2013, 5-7 March. 1-7.

[9] Erna Kakadjian, April Shi, Justin Porter, et al. "Low Impact Drilling Fluid for Deepwater Drilling Frontier", OTC29802 presented at Offshore Technology Conference. 2019, 29-31 October. 1-10.

[10] Luo Jiansheng, Liu Gang, Li Chao, et al. "Research and application of FLAT-PRO synthetic based drilling fluid system in deep water". China Offshore Oil and Gas, 2017, 29 (3): 61-66.

[11] E. van Oort, J. Lee, SPE, J. Friedheim. "New Flat-Rheology Synthetic-Based Mud for Improved Deepwater Drilling", SPE90987 presented at 2004 SPE Annual Technical Conference and Exhibition held in Houston, Texas, U.S.A., 26-29 September. 1-11.

[12] Vivek Gupta, Sakshi Indulkar, Megha Asrani, et al. "An Innovative Rheology Modifier Which Provides Dual Function Achieves Non-Damaging Clay Free System for Reservoir Drilling and Flat Rheology for Deep Water Drilling", SPE193618 presented at SPE International Conference on Oilfield Chemistry, 2019, 8-9 April. 1-12.

[13] Arvind Patek, Sakshi Indulkar, Vikas Chavan, et al. "Clay Free Invert Emulsion Drilling Fluid System- An Innovative Rheology Modifier Which Provides Flat Rheology for Deep Water Drilling and Viscosifier for Clay Free System", SPE192618 presented at Abu Dhabi International Petroleum Exhibition \& Conference, 12-15 November. 1-19.

[14] Shervin Taraghikhah, Mojtaba Kalhor, Mohammadi, et al. "A New Generation of Independent Temperature and Pressure Drilling Fluids System with Flat Rheological Properties, Low Invasion, Higher Shale Stability and Lubricity to Replace Oil Based Mud", SPE196311 presented at SPE/IATMI Asia Pacific Oil \& Gas Conference and Exhibition, 2019, 29-31 October. $1-16$.

[15] Hu Wenjun, Cheng Yusheng, Li Huaike, et al. "Drilling Fluid Technology for Deepwater HTHP Well", Drilling Fluid \& Completion Fluid, 2017, 34 (1): 70-76.

[16] Enrico Squintani, Andrea Uslenghi, Susanna Ferrari, et al. "Deepwater HPHT Drilling through Ultra Narrow PPFG Window: A Case Study by ENI Where the Combination of Continuous Circulation Technology Together with MPD Drilling has been Successfully Applied to Extreme Drilling Environment Condition in HPHT Ultra Deepwater Well", SPE192749 presented at Abu Dhabi International Petroleum Exhibition \& Conference, 2018, 12-15 November 29-31. 1-16.

[17] Li Huaike, Tian Rongjian, Luo Jiansheng et al. "A New Method for the Determination of inhibitation of Amine Derivatives”, Drilling Fluid \& Completion Fluid, 2012, 29 (6): 51-54. 